\title{
When and why is ease of retrieval informative?
}

\author{
PRIYA RAGHUBIR \\ University of California, Berkeley, California \\ and \\ GEETA MENON \\ New York University, New York, New York
}

\begin{abstract}
In two experiments, we examined when and why ease of retrieval of information from memory affects behavioral frequency and attitudinal judgments. Overall, the results suggest that when the subjective experience of ease of retrieval is consistent with the expected ease of retrieval, the content of the information retrieved is used to make judgments. However, when there is a discrepancy between experienced and expected ease of retrieval, the subjective experience of ease of retrieval is used to make judgments. Ease of retrieval is more informative when the discrepancy between experienced and expected ease of retrieval cannot be attributed to task contingencies; when it can, ease of retrieval ceases to be informative.
\end{abstract}

Ask yourself to "name ten restaurants that you go to on a regular basis." Now change the requirement to "name two." If it was difficult to name 10 restaurants, you may believe that the overall population of restaurants in your memory is small, which could mean that you do not go out very often. This is because listing many instances is difficult, and the ease or difficulty with which information comes to mind is itself informative. That is, the more difficult a listing task, the smaller one thinks is the overall population from which an instance can be drawn. Behavioral frequency judgments may, accordingly, reflect the experienced ease or difficulty of recalling information from memory. Note that it is the context and task that would make an individual instance more or less easy to recall, rather than something about the event in and of itself. Said differently, recalling the names of restaurants could be easy or difficult contingent on whether the recall task was to recall just 2 or as many as 10 . It is the task that makes the recall difficult, rather than a specific property of the restaurant. This subjective experience of finding a recall task easy or difficult is referred to as ease of retrieval. This is consistent with Tversky and Kahneman's (1973) availability heuristic, which states that people estimate the frequency of an event as a function of the ease with which it comes to mind. According to Tversky and Kahneman, this is because people believe that the higher the population of events in memory, the easier the recall of any one event from this population. Therefore, when people find an event easy to recall, they make the

G.M. is Professor of Marketing and Harold MacDowell Faculty Fellow at the Leonard N. Stern School of Business, New York University. The authors contributed equally to the development of this article. Correspondence should be addressed to P. Raghubir, Haas School of Business, University of California, Berkeley, CA 94720-1900 (e-mail: raghubir@haas.berkeley.edu). reverse inference, believing that the event is drawn from a larger population in memory.

In the domain of person perception, Schwarz et al. (1991) found that when participants were asked to recall 12 examples of assertive behaviors, they rated themselves as less assertive than when they were asked to recall only 6 examples. Ease of retrieval served an informative function: When a behavior was difficult (vs. easy) to recall, participants inferred that they were lower on the trait exemplifying that behavior. Jacoby, Kelley, Brown, and Jasechko (1989) found that when names come to mind easily, people are perceived to be more famous even when the names are fictitious. Ease of retrieval has also been shown to affect behavioral frequency judgments (Aarts \& Dijksterhuis, 1999), evaluation of one's childhood memories (Brewin \& Stokou, 2002), subjective judgments of the risk of AIDS (Raghubir \& Menon, 1998, 2001), product judgments (Wänke, Bohner, \& Jurkowitsch, 1997), and confidence in judgments (Kelley \& Lindsay, 1993).

However, these effects are not ubiquitous. When ease of retrieval as a cue is actively discredited as a source of information, it ceases to be informative. Earlier experiments have shown that the cue can be discredited if participants are given instructions that the recall task is difficult (Schwarz et al., 1991; Winkielman, Schwarz, \& Belli, 1998), if participants' personal relevance for the judgment is increased (Rothman \& Schwarz, 1998), and if participants are motivated to make accurate judgments (Aarts \& Dijksterhuis, 1999; see Schwarz, 1998, for a review). Ease of retrieval also appears to have different effects for self- versus proxy-judgments. Raghubir and Menon (1998) showed that although ease of retrieval of recalling AIDS-related behaviors was informative for judgments of one's own risk of AIDS, it did not affect judgments of others' risk levels. 


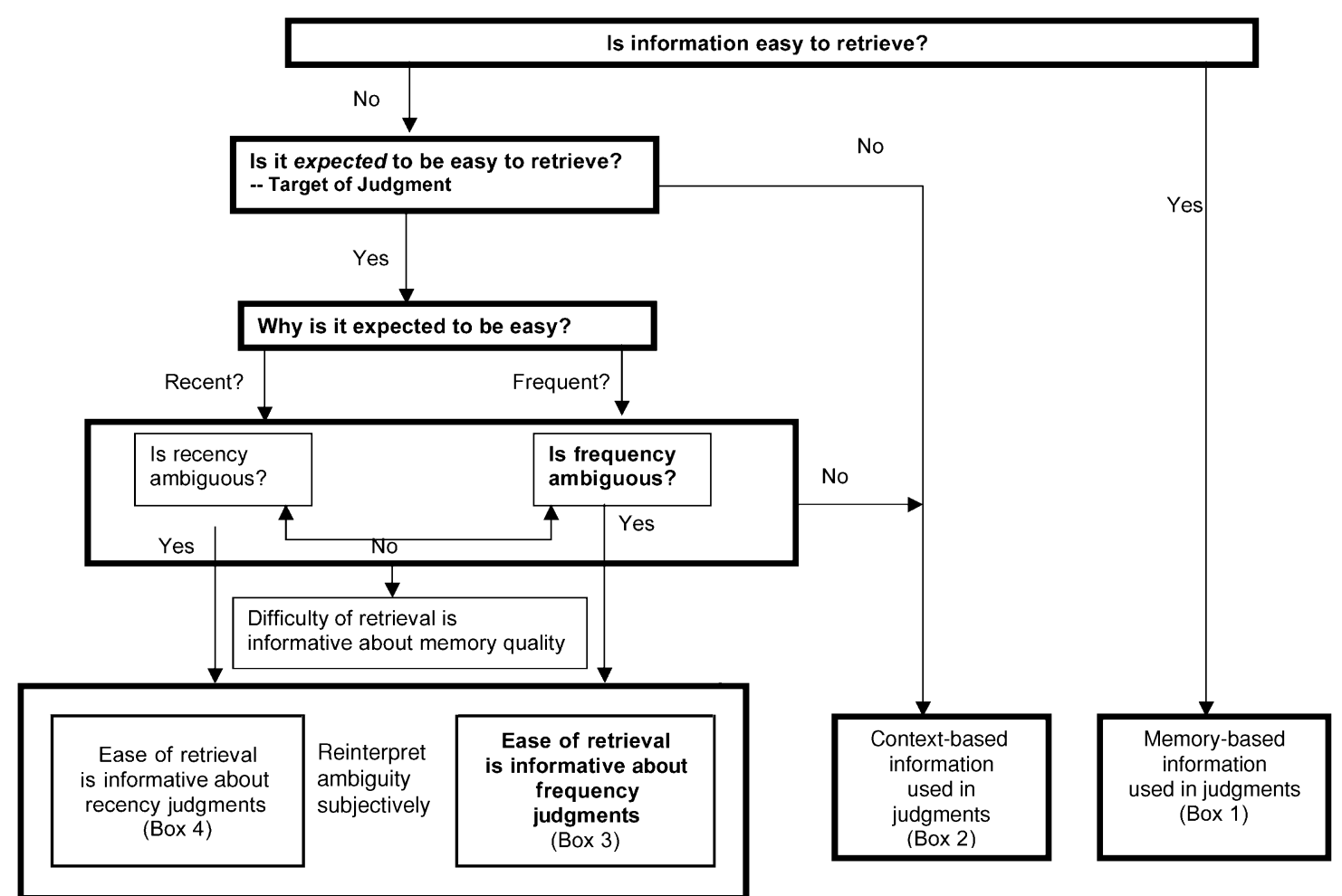

Figure 1. A process model of when and why ease of retrieval is informative.

Using the discrepancy-attribution model (Whittlesea \& Williams, 1998, 2000), we propose that ease of retrieval will be particularly informative when its actual experience deviates from an expected baseline. Recent research on people's naive theories of memory suggest that people have expectations of what information will come easily to mind and what information will not (Skurnik, Schwarz, \& Winkielman, 2000). Information that is frequent, recent, typical, and well represented is expected to be easier to recall than information that is infrequent, distant, atypical, and poorly represented. For example, Winkielman and Schwarz (2001) asked people to recall 4 or 12 memories from their childhood and then manipulated beliefs as to whether pleasant or unpleasant memories fade away. Those who recalled 12 memories (difficult task), believed that they had a happier childhood when they were informed that pleasant childhood memories fade away. Those who recalled 4 memories (easy task) were not influenced by the manipulation of whether pleasant or unpleasant memories fade away (see also Winkielman et al., 1998). However, since these naive theories of memory are malleable and context dependent, we posit that discrepancies in actual and experienced recall difficulty affect the perceived informativeness of ease of retrieval.

In this article, we contribute to a deeper understanding of (1) the manner in which ease of retrieval is informative, (2) the consequences of ease of retrieval on behavioral frequency judgments, attitudes, and intentions,
(3) the antecedent role of episodic recency in moderating the direction by which ease of retrieval is informative of behavioral frequency, and (4) the moderating role of valence of information retrieved on attitudes and behavioral intentions. We now will discuss the conceptual framework within which we make these predictions.

\section{CONCEPTUAL FRAMEWORK}

Figure 1 presents our process-based formulation that delineates when and why ease of retrieval is informative. There are four ways to arrive at judgments, which involve the use of memory-based information (Box 1), context-based information (Box 2), and ease of retrieval as information for either frequency or recency judgments (Boxes 3 and 4). We postulate that experienced ease of retrieval, expectations of ease of retrieval, reasons for this expectation, and the ambiguity of frequency and recency affect the use of the four alternate sources of information for a judgment depicted in Figure 1.

\section{Determinants of Information Inputs for Judgments}

The antecedents to the choice of each of these sources of information, as depicted in the four numbered boxes, will now be briefly described.

Box 1: Memory-based information used in judgments. When information is easy to retrieve, people should use the information retrieved to construct their 
judgment. For example, if people are asked how frequently they brush their teeth in a week, they can easily recall that they do so twice a day and can use this rate to compute their judgment (Menon, 1993, 1997). Similarly, if people are asked how frequently they have traveled on a cruise ship in the last 5 years, they should be able to recall each instance, since the experiences are infrequent, vivid, and memorable. They should then be able to recall and count the total number of cruise ship vacations they made in a 5-year period. In both these cases, the information required for the behavioral frequency judgment is easy to recall, either because each individual instance is highly memorable or because there is an easy heuristic in memory: the rate of occurrence. Since the information is easily recalled, people should be able to use the content of the recalled information to judge the behavioral frequency.

Box 2: Context-based information used in judgments. On the other hand, when instances of a behavior are too numerous to be recalled and counted and respondents do not have access to a rate of occurrence, information is not easy to retrieve. If they are not motivated to be accurate in their judgments, or when the accuracy desired does not warrant the effort required to recall information from memory, people are likely to use contextual cues to compute their judgment. These contextual cues act as a substitute for memory-based information in making a judgment (Sudman \& Bradburn, 1974). This route leads to Box 2 in Figure 1. Boxes 1 and 2 have been explored in the survey methods domain to show that context-based information is used, instead of memory-based information, when it is easy to retrieve and is perceived to be diagnostic of a judgment (e.g., Menon, Raghubir, \& Schwarz, 1995, 1997).

Box 3: Ease of retrieval is informative of frequency judgments. The use of ease of retrieval as a source of information for frequency judgments is the focus of the present article. We propose that when information is not easy to retrieve, respondents question why it is difficult. If there exist readily available reasons that can explain the difficulty of recalling information, respondents stop the questioning process. One example of an available reason is when respondents are informed about the difficulty level of the recall task (Schwarz et al., 1991). Schwarz et al. (1991, Study 2) found that when they informed participants that a difficult task (listing 12 instances of assertive behavior) was indeed difficult, ease of retrieval did not affect the participants' judgments of their own assertiveness: They rated themselves as more assertive when they recalled 12 instances of assertive behavior rather than 6. Similarly, Raghubir and Menon (2001) showed that when people were told that recalling five AIDS-related behaviors was a difficult task, those who were asked to recall behaviors that caused AIDS perceived a higher risk of AIDS than did those who were asked to retrieve behaviors that prevented AIDS. The reverse pattern held when people were not told that recalling five AIDS-related behaviors was a difficult task (see also Menon \& Raghubir, 2003, for a demonstration in the domain of personal computers).
Another example of an available reason for recall difficulty pertains to the entity about whom the judgment is being made: the target of judgment. Ease of retrieval should be more informative about oneself than about another person, since people have no reason to expect that they will have memory-based information about an "average" person.

Thus, if people are told that information about themselves is difficult to recall or if they try to recall another person's behavior knowing that this is difficult to recall, they can explain away the difficulty in recall. In these instances, people can estimate behavioral frequency, using context-based information when the desired accuracy is low (reverting to Box 2), or can make an effort to recall information when the desired accuracy is high (reverting to Box 1). Prior research has shown that respondents use context-based information to make judgments about "the average undergraduate" (Menon, Block, \& Ramanathan, 2002; Menon et al., 1995; Raghubir \& Menon, 1998; Schwarz, Hippler, Deutsch, \& Strack, 1985).

However, when respondents expect information to be easy to recall and it is not, and no ready reason (such as task difficulty) exists to explain the difficulty of recall, the respondents need to resolve this discrepancy. It is difficult to revise one's actual experience of how difficult information was to recall. Thus, the only way to resolve the discrepancy is to revise the expectation of how easy the recall task should be by making inferences regarding the information being recalled.

When a behavior is difficult to recall, people can change their expectancy about how easy it should be to recall, either by amending their beliefs about the frequency of the behavior or by amending their beliefs about the recency of the behavior. This is because people expect frequent and recent behaviors to be easier to recall than infrequent and distant ones (Higgins, 1989). When people do not have an accurate idea of how frequently they engage in a particular behavior (e.g., when behaviors are frequent but performed at irregular intervals, rather than at a fixed periodic rate; cf. Menon, 1993), the actual frequency of their performing a behavior may be ambiguous. For example, people may not know exactly how many sodas they drink in an average week or how many times they have traveled in a car in the past week. In such instances, they can reinterpret the overall frequency of engaging in the behavior. In such a scenario, ease of retrieval will be informative of frequency. If it is difficult to recall a behavior, people may believe that it is based on a smaller population. This is depicted as Box 3 in Figure 1.

For frequently performed behaviors, frequency may be more ambiguous than recency, since the last occasion upon which a frequent behavior has been performed may possibly have been quite recent. The next process allows for the possibility that recency may be more ambiguous than frequency.

Box 4: Ease of retrieval is informative of recency judgments. People also believe that recent behaviors are easier to recall (recency is also an antecedent of accessibility; Higgins, 1989). If it is difficult to recall a behav- 
ior, people may believe that this is so because the behavior did not happen recently (Hintzman, 2003). In this case, ease of retrieval may be informative of recency (Brown \& Schopflocher, 1998). If the overall frequency of performing a behavior is less ambiguous than the recency of performing it, people can resolve the discrepancy between actual and expected ease of retrieval by making an inference about when the behavior was performed, rather than about the number of times the behavior has been performed (Skurnik et al., 2000). This route is depicted as Box 4 in Figure 1.

For the sake of completeness, if people cannot subjectively reinterpret either the frequency or the recency of a behavior (Hintzman, 2001), they may attribute the higher than expected recall difficulty to the quality of their memory (i.e., they are forgetful; Winkielman et al., 1998; see Figure 1) or to the memorability of the event (i.e., the event was not vivid).

\section{Hypotheses}

The focus of this article is on situations in which the actual experience of recalling information is more difficult than was expected. ${ }^{1}$ Our predictions were that task and judgment domains would affect whether ease of retrieval was informative. If information comes to mind easily and this information is expected to be easy to retrieve, there is no discrepancy requiring attribution, and ease of retrieval will not be informative. Furthermore, when people experience difficulty but can attribute it to external factors, such as task difficulty, the experienced ease of retrieval will not be informative for self-judgments. When people make judgments about another person, ease of retrieval will be less informative than when they make judgments about themselves, since people do not expect to have memory-based information about another person. Finally, when information is more difficult to retrieve than was expected, they will use the ease of retrieval to infer the overall frequency of the behavior when the behaviors are recent but will be able to attribute away the discrepancy to time when the behaviors are distant.

In Experiment 1, we examined the effects of ease of retrieval on behavioral and attitude judgments as a function of whether the experienced ease of retrieval was expected or unexpected and whether there existed a reason for the discrepancy when it existed. In Experiment 2, we examined the effects of ease of retrieval when experiences diverged from expectations but respondents could attribute this divergence to the task. ${ }^{2}$

\section{EXPERIMENT 1}

Previous research has indicated that the estimation of frequency judgments has a subjective element affected by the context in which such information is elicited (Blair \& Burton, 1987; Burton \& Blair, 1991; Menon, 1993, 1997; Menon et al., 1995, 1997; Raghubir \& Menon, 1996; Schwarz, 1990, 1998; Winkielman \& Schwarz, 2001; Winkielman et al., 1998). In the domain of ease of retrieval, Aarts and Dijksterhuis (1999) showed that when people were asked to recall eight instances of destinations that they had gone to using a bicycle (a difficult task), they estimated that they had used their bicycle less often than they did when they were asked to only recall three instances (an easy task).

In the present experiment, we examined this effect in a different domain and extended the investigation to assess whether estimates of past frequency carry over to attitudinal judgments. The behavior we chose was eating at restaurants, a behavior frequently engaged in by the participants used in this study and accounting for a large proportion of their total weekly expense. ${ }^{3}$ If respondents are asked to recall two restaurants where they have had a good experience, they should find this task easy and infer that they have eaten at many good restaurants in the past. They should be more satisfied with their overall eating out experience and should be more likely to eat out in the future, as compared with those who are asked to recall eight such experiences (a more difficult task). Therefore, when people are asked to recall positive experiences, they should be more satisfied and have higher intentions to engage in the behavior again when behaviors are easier to recall. Analogously, when asked to recall negative experiences, respondents should be less satisfied and have lower intentions to engage in the behavior again when such behaviors come to mind easily. We tested these predictions in Experiment 1 as a function of the discrepancy between experienced and expected ease of retrieval.

\section{Method}

Design. We used a 2 (number of items recalled: 2 vs. 8$) \times 2$ (experience of information: positive vs. negative) full-factorial betweensubjects design. Ninety-four students enrolled in an introductory marketing course at New York University took part in the experiment to complete a course requirement.

Procedure. Following Schwarz et al.'s (1991) paradigmatic procedure, we asked the participants to list the last two (high ease of retrieval) or eight (low ease of retrieval) times that they had eaten at a restaurant. To manipulate the valence of the information retrieved, we asked the participants to recall either positive or negative experiences. The specific instructions read as follows:

Please think of regular, sit-down restaurants (where there are waiters/ waitresses, a menu, table service, etc.) that you have eaten in recently. Please list $<$ TWO/EIGHT $>$ restaurant visits where you had a $<$ GOOD/BAD $>$ time. Please note that we are interested only in $<$ POSITIVE/NEGATIVE $>$ experiences that you had at restaurants.

Next, to measure behavioral frequencies, we asked respondents to estimate (1) objective frequencies (i.e., how many times a month they generally eat out, using an open-ended format), (2) subjective frequencies (i.e., how many times a month they generally eat out, using a scale anchored at $1=$ rarely and $7=$ frequently), and ( 3 ) expense (i.e., how many dollars they had spent eating out at restaurants since January 1 of the year).

We used a set of five measures to elicit attitudes and intentions, the first two tapping attitudes and the latter three tapping predictions of future behavior. These were (1) satisfaction with experiences (participants rated how satisfied they were with their eating out experiences on a 7-point semantic differential scale anchored at not at all and very satisfied), (2) attitudes toward eating out (participants used four 7-point semantic differential scales anchored at 
Table 1

Experiment1 Results: Manipulation Checks, and Behavioral Frequency and Expense-Related Judgments

\begin{tabular}{|c|c|c|c|c|c|c|c|c|}
\hline \multirow[b]{3}{*}{ Measure } & \multicolumn{4}{|c|}{ Positive Experiences } & \multicolumn{4}{|c|}{ Negative Experiences } \\
\hline & \multicolumn{2}{|c|}{ Recall 2} & \multicolumn{2}{|c|}{ Recall 8} & \multicolumn{2}{|c|}{ Recall 2} & \multicolumn{2}{|c|}{ Recall 8} \\
\hline & $M$ & $S D$ & $M$ & $S D$ & $M$ & $S D$ & $M$ & $S D$ \\
\hline \multicolumn{9}{|c|}{ Manipulation Checks } \\
\hline Actual ease of retrieval: four-item difficulty index* & 3.1 & 1.7 & 3.9 & 1.6 & 2.9 & 1.3 & 5.1 & 1.3 \\
\hline Perceived ease of retrieval: two-item difficulty index* & 2.7 & 1.3 & 4.1 & 1.3 & 2.7 & 1.3 & 4.2 & 1.1 \\
\hline Valence: average valence rating $(-3 \text { to }+3)^{\dagger}$ & 2.2 & 0.6 & 2.0 & 0.5 & $(1.7)$ & 1.0 & $(1.5)$ & 0.8 \\
\hline \multicolumn{9}{|c|}{ Behavioral Frequency and Expense-Related Judgments } \\
\hline Open-ended frequency for a month & 12.1 & 13.7 & 6.6 & 8.0 & 8.7 & 7.9 & 5.3 & 4.2 \\
\hline Closed-ended frequency* & 5.1 & 1.5 & 4.1 & 1.3 & 4.8 & 1.4 & 3.5 & 1.8 \\
\hline Dollars spent eating at restaurants since January $1 \ddagger$ & 798 & 1,036 & 595 & 695 & 884 & 890 & 496 & 415 \\
\hline
\end{tabular}

${ }^{\star}$ Elicited using scales of 1-7. †Negative numbers are in parentheses. ${ }^{\dagger}$ Dollar amounts are reported in round dollars.

boring-fun, unexciting-exciting, nonsocial-social, and unpleasantpleasant that we combined to form the attitude index; Cronbach's $\alpha=.91$ ), (3) prediction of positive experience (respondents rated their prediction of whether the next eating experience was going to be positive, using a 7-point scale anchored at not at all likely and very likely), (4) prediction of negative experience (respondents rated their prediction of whether the next eating out experience was going to be negative, using a 7-point scale anchored at not at all likely and very likely), and (5) behavioral intention (the intention of initiating the next eating out incident was elicited on a 7-point likelihood scale anchored at not at all likely and very likely).

As manipulation checks, we followed the method used by Menon et al. $(1995,1997)$ and elicited ratings on four 7-point scales to measure the task difficulty of recalling experiences at restaurants, anchored at (1) not at all difficult and very difficult, (2) no effort and a lot of effort, (3) no time and a lot of time, and (4) no thought and a lot of thought. We computed a difficulty index on the basis of these measures (Cronbach's $\alpha=.95$ ).

At the end of the study, we asked the participants how the difficulty of the actual task of listing the experiences compared with their expectations, using two 7-point semantic differential scales anchored at much easier/much more difficult and much less effortful/ much more effortful. These were combined to form the comparative difficulty index (Cronbach's $\alpha=.91$ ).

To control for the possibility that longer listing tasks dilute the valence of the information recalled (i.e., when asked to recall eight positive instances, the later instances recalled are less positive than the earlier instances recalled, leading to the average instance recalled being less positive in the longer listing task), we asked the participants to rate each incident. At the end of the questionnaire, they returned to their listings and rated each on a scale of -3 (negative) to +3 (positive), with 0 indicating a neutral incident. These ratings were used to compute an overall valence of instances recalled, a measure that also acts as a manipulation check for the valence of retrieved information.

The procedure took around $20 \mathrm{~min}$.

\section{Results and Discussion}

Manipulation checks. We conducted three separate manipulation checks. To confirm that the longer listing task was more difficult than the shorter listing task, we examined the four-item difficulty index. To confirm that the longer listing task was more difficult than it was expected to be, we examined the comparative difficulty index. And to confirm that more positive experiences were listed in the positive valence condition, we examined the overall valence of instances recalled.
The four-item difficulty index measured respondents' self-reports of how easy or difficult it was to recall (two or eight) restaurants (elicited on a 1-7 scale). The average ratings by condition are provided in the top half of Table 1. A 2 (number of items recalled: 2 vs. 8 ) $\times 2$ (valence: positive or negative) analysis of variance (ANOVA) on the difficulty index showed the predicted main effect of number of items recalled $\left[M_{2}=3.0\right.$ vs. $M_{8}=4.5$; $\left.F(1,90)=23.23, M S_{\mathrm{e}}=2.21, p<.001\right]$. This effect was qualified by an interaction with valence of the information retrieved $[F(1,90)=4.90, p<.05]$. Given the interaction, we checked that recalling eight experiences was more difficult than recalling two experiences, both when the experiences were negative $\left[M_{2 \mathrm{~N}}=2.9\right.$ vs. $M_{8 \mathrm{~N}}=5.1$; contrast, $F(1,91)=23.67, p<.01]$ and when they were positive $\left[M_{2 \mathrm{P}}=3.1\right.$ vs. $M_{8 \mathrm{P}}=3.9$; contrast, $F(1,91)=$ $3.61, p<.06]$. Therefore, the longer listing task was more difficult than the shorter listing task.

To check that the longer listing task was also more difficult than it was expected to be, we analyzed the comparative difficulty index that measured self-reports of whether the recall task was easier or more difficult than the respondent had expected. Deviations of means from the midpoint of 4 indicate a discrepancy between the expected and the experienced ease of retrieval. Means are provided in the second row of data in the top half of Table 1. A 2 (valence: positive or negative) $\times 2$ (number of items recalled: 2 vs. 8 ) ANOVA revealed a significant main effect of number of items recalled: The recall eight task was perceived to be more difficult than expected, as compared with the recall two task $\left[M_{2}=4.2\right.$ vs. $M_{8}=$ 4.7; $\left.F(1,90)=5.71, M S_{\mathrm{e}}=1.35, p<.05\right]$ and the mean was also significantly higher than the scale midpoint $[t(43)=3.91, p<.01]$. The mean in the recall two task was no different from the scale midpoint $[t(49)=1.07$, $p>.25]$. This indicates that people should find the higher than expected difficulty of recalling eight instances more informative than the as-expected ease of recalling two instances. Overall, negative experiences were rated as more difficult to recall than was expected, as compared with positive experiences $\left[M_{\mathrm{N}}=4.7 \mathrm{vs}\right.$. $\left.M_{\mathrm{P}}=4.1 ; F(1,90)=5.71, p<.05\right]$. Their average mean 
Table 2

Experiment 1 Results: Means and Standard Deviations for Attitudes and Behavioral Intentions

\begin{tabular}{|c|c|c|c|c|c|c|c|c|}
\hline \multirow[b]{3}{*}{ Measure } & \multicolumn{4}{|c|}{ Positive Experiences } & \multicolumn{4}{|c|}{ Negative Experiences } \\
\hline & \multicolumn{2}{|c|}{ Recall 2} & \multicolumn{2}{|c|}{ Recall 8} & \multicolumn{2}{|c|}{ Recall 2} & \multicolumn{2}{|c|}{ Recall 8} \\
\hline & $M$ & $S D$ & $M$ & $S D$ & $M$ & $S D$ & $M$ & $S D$ \\
\hline Satisfaction with eating out es & 5.5 & 1.0 & 4.6 & 1.4 & 4.0 & 1.6 & 5.3 & 0.9 \\
\hline Attitude toward eating out (index of four items; $\alpha=.91$ ) & 5.9 & 1.0 & 5.5 & 1.0 & 5.1 & 1.5 & 5.9 & 0.7 \\
\hline Likelihood that next eating out experience will be positive* & 5.5 & 1.2 & 4.9 & 1.5 & 4.6 & 1.8 & 5.5 & 1.0 \\
\hline Likelihood that next eating out experience will be negative* & 3.2 & 1.3 & 3.6 & 1.5 & 3.7 & 1.6 & 3.0 & 1.3 \\
\hline Likelihood of initiating next eating out incident* & 4.5 & 1.9 & 3.7 & 1.8 & 3.4 & 2.0 & 4.4 & 1.6 \\
\hline
\end{tabular}

*Elicited using $1=$ not at all; 7 = very.

was also higher than the scale midpoint, reflecting that this task was more difficult than was anticipated $[t(46)=$ $4.74, p<.01]$. The experience of recalling positive experiences was no different than it was expected to be (vs. scale midpoint 4: $t<1$ ). Thus, when respondents are asked to recall eight negative instances, they find this task more difficult than they expect, whereas in other conditions, the task is no more or less difficult than it is expected to be.

Finally, to confirm that the respondents listed more positive experiences in the positive (vs. the negative) valence condition, we analyzed the overall valence of instances recalled. A 2 (number of items recalled) $\times 2$ (valence) ANOVA on the respondents' self-ratings of each experience that they had recalled (elicited on a -3 to +3 scale, with 0 indicating neutrality) revealed a main effect of valence $\left[F(1,90)=571.19, M S_{\mathrm{e}}=0.55, p<\right.$ $.001]$, such that experiences were rated as more negative in the negative experience conditions $\left(M_{\mathrm{N}}=-1.6\right)$ than in the positive experience conditions $\left(M_{\mathrm{P}}=2.1\right)$. This analysis also ruled out the possibility that the length of the listing task affected the valence of the experiences recalled, since the overall valence rating did not vary as a function of the ease-of-retrieval manipulation.

To summarize, we confirmed that the longer listing task was more difficult than the shorter one, was more difficult than it was expected to be, and did not affect the content of the information recalled. When the respondents were asked to recall positive information, the information they recalled was more positive than when they were asked to recall negative information. Thus, ease of retrieval and valence were successfully and orthogonally manipulated.

Self-reports of behavioral frequencies and expenditures. We predicted that when the participants recalled eight experiences (a difficult task), they would report that they ate out less frequently than when they recalled two experiences (a relatively easier task), irrespective of whether they recalled positive or negative experiences. We measured frequency in three ways: subjective frequency (SF; ratings from 1 to 7, with higher numbers indicating higher frequency), objective frequency (OF; open-ended estimate of the number of times a month a person ate out on average), and expense estimates (Exp; dollars spent eating out since January 1). The results are presented in the bottom half of Table 1 . Separate $2 \times 2$
ANOVAs on each of the three measures revealed significant main effects of the number of items recalled $\left[F_{\mathrm{SF}}(1,90)=12.01, M S_{\mathrm{eSF}}=2.35 ; F_{\mathrm{OF}}(1,90)=5.32\right.$, $M S_{\mathrm{eOF}}=86.16 ; F_{\mathrm{Exp}}(1,90)=3.14, M S_{\mathrm{eExp}}=650,809.25$; all $p \mathrm{~s}<.01]$. No other effect was significant in any of the ANOVAs. The respondents rated that they ate out more frequently on the 7-point rarely-frequently scale when they recalled two versus eight occasions $\left(M_{2 \mathrm{SF}}=4.9 \mathrm{vs}\right.$. $\left.M_{8 \mathrm{SF}}=3.8\right)$. Similarly, the respondents estimated they went to restaurants more times in an average month when they recalled only two versus eight restaurants $\left(M_{2 \mathrm{OF}}=10.4\right.$ vs. $\left.M_{8 \mathrm{OF}}=6.0\right)$ and estimated that they had spent more on eating out since January 1 of that year $\left(M_{2 \mathrm{Exp}}=841.31\right.$ vs. $\left.M_{8 \mathrm{Exp}}=545.91\right)$. To summarize, the estimated frequency of eating out was higher the easier it was to recall restaurant experiences. In other words, the ease of retrieval of information from memory was informative of behavioral frequency judgments.

Attitudes and behavioral intentions. We predicted that attitudes toward dining out and intentions to eat out in the future would be more favorable when the participants were asked to recall positive experiences and these experiences were easier to retrieve (i.e., $2_{\mathrm{P}}>8_{\mathrm{P}}$ ). However, attitudes toward dining out and intentions to eat out in the future would be less favorable when the participants were asked to recall negative experiences and this information was easier to retrieve (i.e., $2_{\mathrm{N}}<8_{\mathrm{N}}$ ).

Attitudes toward eating out were elicited with two separate measures using 7-point semantic differential scales, with higher numbers reflecting more favorable attitudes: degree of satisfaction with eating out experiences and the attitude index (average of ratings on boring-fun, unexciting-exciting, nonsocial-social, and unpleasantpleasant). The results are presented in the top half of Table 2. Univariate 2 (number of items recalled: 2 vs. 8) $\times 2$ (experience: positive vs. negative) ANOVAs on these measures indicated the predicted significant interaction (see Table 2). The pattern of means was similar for the two measures. The participants were more satisfied when asked to recall two (vs. eight) items in the positive experience condition $\left[M_{2 \mathrm{P}}=5.5\right.$ vs. $M_{8 \mathrm{P}}=4.6$; contrast, $F(1,91)=5.77, p<.05]$ but were less satisfied when asked to recall two (vs. eight) items in the negative experience condition $\left[M_{2 \mathrm{~N}}=4.0\right.$ vs. $M_{8 \mathrm{~N}}=5.3$; contrast, $F(1,91)=12.35, p<.05$; interaction, $F(1,90)=$ 
Table 3

Experiment 2 Results: Manipulation Checks

\begin{tabular}{|c|c|c|c|c|c|c|c|c|c|}
\hline \multirow[b]{3}{*}{ Measure } & & \multicolumn{4}{|c|}{ Sit-Down Restaurants } & \multicolumn{4}{|c|}{ Fast-Food Restaurants } \\
\hline & & \multicolumn{2}{|c|}{ Recall 2} & \multicolumn{2}{|c|}{ Recall 10} & \multicolumn{2}{|c|}{ Recall 2} & \multicolumn{2}{|c|}{ Recall 10} \\
\hline & & $M$ & $S D$ & $M$ & $S D$ & $M$ & $S D$ & $M$ & $S D$ \\
\hline \multirow[t]{2}{*}{ Ease of retrieval: difficulty index* } & Recent & 3.3 & 1.5 & 4.3 & 1.0 & 2.8 & 1.2 & 4.6 & 1.0 \\
\hline & Not recent & 3.2 & 1.6 & 3.8 & 1.7 & 3.4 & 1.4 & 4.1 & 1.2 \\
\hline \multirow[t]{2}{*}{ Valence: average valence rating $(-3$ to +3$)$} & Recent & 1.8 & 1.3 & 1.6 & 0.8 & 0.6 & 1.2 & 1.2 & 0.7 \\
\hline & Not recent & 1.8 & 1.0 & 2.0 & 0.6 & 0.9 & 0.8 & 0.8 & 0.6 \\
\hline
\end{tabular}

${ }^{*}$ Using four 7-point scales, with higher numbers indicating greater difficulty.

$\left.16.92, M S_{\mathrm{e}}=1.68, p<.001\right]$. No other effect was significant. Analogously, when positive experiences were recalled, the four-item attitude index was more favorable when the participants were asked to recall two (vs. eight) items $\left(M_{2 \mathrm{P}}=6.0\right.$ vs. $\left.M_{8 \mathrm{P}}=5.5\right)$, but when negative experiences were recalled, the attitude index was less favorable when two experiences were recalled than when eight experiences were recalled $\left[M_{2 \mathrm{~N}}=5.1\right.$ vs. $M_{8 \mathrm{~N}}=$ 6.0 ; interaction, $\left.F(1,90)=8.04, M S_{\mathrm{e}}=1.22, p<.001\right]$. To summarize, the greater the amount of positive information that is recalled, the less favorable the attitude, and the greater the amount of negative information that is recalled, the more favorable the attitude. In other words, attitudes reflect ease of retrieval, rather than the content of the information recalled.

Intentions were elicited with three measures using 7point scales anchored at not at all and very likely, with higher numbers indicating a higher likelihood: prediction of how likely it was that the next eating out experience would be positive, prediction of whether the next eating out experience would be negative, and prediction that the respondent would initiate the next eating out incident (behavioral intention). The results are presented in the bottom half of Table 2. Univariate 2 (number of items recalled: recall two vs. eight) $\times 2$ (experience: positive vs. negative) ANOVAs on these three measures indicated the predicted significant interaction [predicted positive experience, $F(1,90)=6.93, M S_{e}=1.96, p<$ .001 ; predicted negative experience, $F(1,90)=3.15$, $M S_{\mathrm{e}}=2.13, p<.001$; prediction of initiating next incident, $\left.F(1,90)=5.31, M S_{\mathrm{e}}=3.42, p<.001\right]$. The means for all measures followed the same pattern, reflecting that the respondents predicted that they would be more likely to have a positive experience, would be less likely to have a negative experience, and would be more likely to initiate the next eating out incident when they recalled two positive experiences than when they recalled eight positive experiences (see Table 2). The reverse patterns obtained when they were asked to recall negative experiences: Predictions were less favorable when two negative, versus eight negative, experiences were recalled. All contrasts between the recall-two and recall-eight conditions are significant within each experience (positive/ negative) condition for each of these measures.

The results in Experiment 1 revealed that the ease with which information can be retrieved from memory affects people when they arrive at OF and SF judgments. We replicated and extended the literature on the subjectivity of "factual" frequency information (Aarts \& Dijksterhuis, 1999; Menon et al., 1995; Schwarz et al., 1985). Furthermore, we predicted and showed that ease of retrieval is informative because the experienced difficulty diverges from the expected difficulty and that this discrepancy can be attributed to the frequency with which a behavior is performed. Overall, the pattern of means for attitudes and intentions follows the discrepancy between expected and experienced ease of retrieval: When information is more difficult than expected to recall (recalling eight experiences), the ease of retrieval of the information follows through to and overwhelms judgments based on the content of the information recalled. When respondents recall few positive experiences, these are easy to recall, and the respondents have more favorable attitudes than when they recall many positive experiences that are more difficult to recall than expected. Furthermore, recalling a greater number of negative experiences leads to more favorable attitudes than does recalling few negative experiences, since it is more difficult than expected to recall a large number of negative experiences.

\section{EXPERIMENT 2}

\section{Recency of Occurrence}

In Experiment 2, we examined the moderating effect of recency on the informativeness of ease of retrieval for frequency judgments. In Experiment 1, the participants were asked to recall recent events. Events that occurred recently can be expected to be easier to recall than those that happened in the less recent past. If people are asked to recall less recent (or distant) events, they should be able to attribute the difficulty of recall to the events' not being recent, and ease of retrieval manipulated through the number of items recalled (2-10 incidents) should be less informative. In essence, people will believe that they cannot recall information about themselves easily, because the events occurred a long time ago. This implies that the number of instances recalled and the recency of the events will interact to affect self-reports of behavioral frequencies, so that for recent events, recalling 2 incidents will result in higher frequency estimates than recalling 10 incidents (as was observed in Experiment 1), but not necessarily for more distant events. 
Table 4

Experiment 2 Results: Behavioral Frequency and Expense-Related Judgments

\begin{tabular}{|c|c|c|c|c|c|c|c|c|c|}
\hline \multirow{3}{*}{\multicolumn{2}{|c|}{ Measure }} & \multicolumn{4}{|c|}{ Sit-Down Restaurants } & \multicolumn{4}{|c|}{ Fast-Food Restaurants } \\
\hline & & \multicolumn{2}{|c|}{ Recall 2} & \multicolumn{2}{|c|}{ Recall 10} & \multicolumn{2}{|c|}{ Recall 2} & \multicolumn{2}{|c|}{ Recall 10} \\
\hline & & $M$ & $S D$ & $M$ & $S D$ & $M$ & $\overline{S D}$ & $M$ & $S D$ \\
\hline \multicolumn{10}{|c|}{ Behavioral Frequency Judgments } \\
\hline \multirow[t]{2}{*}{ Open-ended frequency for a month } & Recent & 19.4 & 5.4 & 9.2 & 6.3 & 14.1 & 7.2 & 9.7 & 8.2 \\
\hline & Not recent & 8.9 & 6.3 & 8.0 & 3.6 & 12.9 & 6.9 & 14.9 & 9.6 \\
\hline \multirow[t]{2}{*}{ Closed-ended frequency $(1=$ rarely; $7=$ frequently $)$} & Recent & 5.6 & 0.9 & 4.2 & 1.7 & 5.4 & 1.2 & 4.5 & 1.2 \\
\hline & Not recent & 4.9 & 1.4 & 5.1 & 1.4 & 5.0 & 1.5 & 5.1 & 1.3 \\
\hline \multicolumn{10}{|c|}{ Expense-Related Judgments } \\
\hline \multirow[t]{2}{*}{ Dollars spent eating at sit-down restaurants since January 1} & Recent & 952 & 836 & 267 & 173 & 904 & 733 & 329 & 266 \\
\hline & Not recent & 452 & 216 & 538 & 695 & 422 & 224 & 477 & 392 \\
\hline \multirow[t]{2}{*}{ Dollars spent eating at fast-food restaurants since January 1} & Recent & 556 & 919 & 155 & 201 & 373 & 461 & 174 & 139 \\
\hline & Not recent & 180 & 155 & 173 & 175 & 245 & 243 & 276 & 438 \\
\hline
\end{tabular}

Note-Dollar amounts are reported in round dollars.

\section{Target of Judgment}

The proposed framework suggests that ease of retrieval should not be informative for estimates about a nonself target. In the present context, the respondents may use the number of incidents that they are asked to recall as a cue for the typical number of times that an average person engages in the behavior being queried. This should be the case regardless of whether they are queried about recent or distant time frames, because reports about the average other are context based (see Menon et al., 1995, 1997). Note that the effects posited for the average person are the opposite of those posited for self-reports, since the former are context based and the latter are memory based (see Menon et al., 2002, for a discussion of these effects). Although difficulty of recalling information may be informative for oneself when it is expected to be easy to recall, there is no reason to expect information to be easy to recall for others, so it should not exert an effect. Therefore, people may use a simple contextual cue to estimate frequencies for an "average person"- that is, the more restaurants they are asked to recall, the more they believe others eat out. This implies a simple main effect of number of instances recalled, but in the opposite direction to that expected for self-reports: Estimated frequencies of an average person should be higher when the task is to recall 10 versus 2 incidents.

\footnotetext{
Method

Pretest. We conducted a pretest to confirm that recent experiences are expected to be easier to recall than experiences from the more distant past and that recalling two experiences from the distant past is expected to be easier than recalling eight experiences from the distant past. Participants drawn from the same pool as that in Experiment $1(n=14)$ were asked to rate the difficulty of hypothetically recalling two versus eight restaurant experiences from the current term (Fall) or the past term (Spring), using a 7-point scale anchored at $1=$ not at all difficult and $7=$ very difficult. A withinsubjects 2 (time: recent vs. distant) $\times 2$ (number of items recalled: two vs. eight) ANOVA showed a main effect of time and number of items recalled and their interaction $[F(1,13)=17.33,20.77$, and 6.30, respectively; $M S_{\mathrm{e}} \mathrm{s}=0.81,4.46$, and 0.18 ; all $\left.p \mathrm{~s}<.05\right]$. Recalling two restaurant experiences from the current term was rated as the easiest $(M=1.57)$, followed by two experiences from the past
}

term $(M=2.29)$, eight experiences from the current term $(M=$ $3.86)$, and finally, eight experiences from the past term $(M=5.14)$. All contrasts were significant.

Design. We used a 2 (number of instances retrieved: 2 vs. 10) $\times$ 2 (recency manipulated through reference time frame: in the last four months [July-October] vs. in the previous Spring semester [January-April] $\times 2$ (valence of retrieved information: positive vs. less positive) between-subjects design. The experiment was conducted at the end of October. To provide convergent validity for the results in Experiment 1, we manipulated the valence of the experience in a subtler manner than was done in Experiment 1. More positive experiences were obtained by asking people to recall incidents of eating out at "regular sit-down restaurants" (SDRs), and less positive experiences were obtained by asking people to recall incidents at "fast-food restaurants" (FFRs). One hundred sixty-eight undergraduate students participated in this experiment for partial course credit. Degrees of freedom in the multivariate tests reported in some tests are lower, due to partial nonresponse.

Procedure. The participants were run in groups of $12-15$. They were assigned at random to one of the eight experimental conditions. They first recalled 2 (or 10) instances of eating out at an SDR (vs. an FFR) in the last 4 months of the ongoing Fall semester (vs. 4 months of the prior Spring semester) and then completed the dependent measures. ${ }^{4}$ As in Experiment 1, we followed this up by measuring behavioral frequencies eliciting: (1) SFs (ratings of how often a person eats out, using a scale anchored at rarely $=1$ and frequently $=7$ ), (2) OFs (open-ended estimates of how many times a month a person generally eats out), and (3) Exp (estimates of how many dollars a person has spent in regular SDRs and FFRs since January 1). Next, satisfaction and attitudes were measured as in Experiment 1 . To measure intentions, we asked the participants to rate the likelihood of (1) initiating the next eating out incident, (2) choosing a regular SDR the next time they eat out, and (3) choosing an FFR the next time they eat out, using 7-point scales anchored at not at all and very likely.

We also asked the respondents to estimate how often the average undergraduate at the university they attend eats out at the specific type of restaurant in a month, elicited using an open-ended question and a subjective 7-point scale. We expected that difficulty of recall would be informative of self-judgments but that judgments of another target would be based on a simpler contextual cue: length of the listing task.

As in Experiment 1, to measure whether the manipulations of information ease of retrieval worked as intended, we asked the respondents to rate the difficulty of the recall task, using the fouritem difficulty index, as in Experiment 1 (Cronbach's $\alpha=.89$ ). Furthermore, as in Experiment 1, we asked the participants at the 
end of the questionnaire to go back to the page where they had recalled instances and rate each incident they had listed on a scale of -3 (negative) to +3 (positive), with 0 indicating a neutral incident.

\section{Results and Discussion}

Manipulation checks. We wished to ensure that recalling 2 instances was easier than recalling 10 instances and that eating at an SDR was evaluated more favorably than eating at an FFR. Perception of task difficulty was assessed with a rating ranging from 1 to 7 , with higher numbers indicating higher difficulty, and the valence of the recalled items was assessed with a rating ranging from -3 to +3 . The average ratings are shown in Table 3 . A 2 (valence: sit-down vs. fast food) $\times 2$ (number of items recalled: 2 vs. 10) $\times 2$ (time: recent vs. distant) ANOVA on the difficulty index revealed a significant main effect of number of experiences recalled $\left[F(1,155)=21.85, M S_{\mathrm{e}}=1.82, p<.01\right]$. As was expected, recalling 2 instances was rated as easier than recalling $10\left(M_{2}=3.2\right.$ vs. $M_{10}=4.2$, respectively). No other effects were significant at $p<.05$. Therefore, our manipulation worked as intended.

Similarly, a $2 \times 2 \times 2$ ANOVA on average valence ratings of experiences across all instances recalled revealed only a significant main effect of valence $[F(1,155)=$ $\left.48.15, M S_{\mathrm{e}}=0.81, p<.01\right]$, so that eating out at regular restaurants was rated more favorably than eating out at FFRs $\left(M_{\mathrm{SDR}}=1.8, M_{\mathrm{FFR}}=0.8\right)$. That the number of instances recalled did not show a main effect or interaction $(p s>.10)$ indicates that longer listing tasks did not lead to less positive experiences being recalled. In short, it rules out the alternate explanation that the longer listing task prompts the recall of valence-inconsistent information. Note that these means are all on the positive side of the scale, indicating that our manipulation of valence is positive versus less positive, rather than positive versus negative.

Self-reports of behavioral frequencies and expenditures. To examine the effects of ease of retrieval on behavioral frequencies and expenditures, we used four measures: Three of them were elicited using an openended format (average frequency of eating out in a month, Exp at SDRs since January 1, and Exp at FFRs since January 1), and one was elicited using a subjective rating of how rarely or frequently a person eats out, using a 7point scale with a higher number indicating a higher SF. The means by condition are given in Table 4 . Each of these four measures was subjected to a $2 \times 2 \times 2$ (valence $\times$ number of items recalled $\times$ recency of time frame) ANOVA. The interaction between recency of time frame and the number of items recalled was significant for all measures [OF, $F(1,159)=13.38, M S_{\mathrm{e}}=$ $49.70, p<.01$; SF, $F(1,159)=9.42, M S_{\mathrm{e}}=1.82, p<$ .01 ; Exp at SDRs, $F(1,159)=19.76, M S_{\mathrm{e}}=258,206.63$, $p<.01$; Exp at FFRs, $F(1,159)=5.73, M S_{\mathrm{e}}=$ $176,925.67, p<.01]$.

For all measures, the effect of the number of items recalled (i.e., ease of retrieval) was stronger in the recent time frame than in the less recent time frame. Specifically, when queried about a recent time frame (i.e., the last four months), the participants reported a higher SF of eating out when they were asked to recall 2 instances $\left(M_{2}=5.5\right)$ than when asked to recall $10\left(M_{10}=4.4\right.$; contrast, $p<.05)$. When a less recent time frame was queried (i.e., the previous Spring), however, there was no difference when they were asked to recall 2 instances $\left(M_{2}=\right.$ $5.0)$ or $10\left(M_{10}=5.1\right.$; contrast, $\left.F<1\right)$. The same pattern is evident with other measures: The respondents estimated they had eaten out more often when they recalled 2 recent instances $\left(M_{\mathrm{SDR}-2}=19.4\right.$ and $\left.M_{\mathrm{FFR}-2}=14.1\right)$ than when they recalled 10 recent instances $\left(M_{\mathrm{SDR}}=9.2\right.$ and $\left.M_{\mathrm{FFR}}=9.7\right)$. However, when the experiences were in the relatively distant past, there was no difference as a function of the number of restaurants recalled $\left(M_{\mathrm{SDR}-2}=\right.$ 8.9 vs. $M_{\mathrm{SDR}-10}=8.0$ for SDRs, and $M_{\mathrm{FFR}-2}=12.9 \mathrm{vs}$. $M_{\mathrm{FFR}-10}=14.9$ for FFRs).

Exp for SDRs was also higher when 2 recent instances were recalled $\left(M_{\mathrm{SDR}-2}=\$ 952\right.$ and $\left.M_{\mathrm{FFR}-2}=\$ 904\right)$ than when 10 recent instances were recalled $\left(M_{\mathrm{SDR}-10}=\$ 267\right.$ and $\left.M_{\mathrm{SDR}-10}=\$ 329\right)$. However, as with the other measures, the effects disappeared when the estimate was for the relatively distant past for both SDRs $\left(M_{\mathrm{SDR}-2}=\$ 452\right.$ vs. $\left.M_{\mathrm{SDR}-10}=\$ 538\right)$ and FFRs $\left(M_{\mathrm{FFR}-2}=\$ 422 \mathrm{vs}\right.$. $\left.M_{\mathrm{FFR}-10}=\$ 477\right)$. The same pattern was replicated for Exp for FFRs (see the means in Table 4). ${ }^{5}$

Attitudes and behavioral intentions. Attitudes were elicited as in Experiment1: satisfaction with eating out experiences and the four-item attitude index, both measured using 7-point scales, with higher numbers indicating more favorable attitudes. Intentions were measured using three 7-point likelihood measures: initiating an eating-out incident (as in Experiment 1), choosing an SDR, and choosing an FFR. Higher numbers indicate a higher likelihood. Means by condition for each of the five measures are presented in Table 5. The analysis was a $2 \times 2 \times 2$ ANOVA on each measure. The predicted three-way interaction was significant for each of the measures [rated satisfaction, $F(1,159)=9.90, M S_{\mathrm{e}}=$ $0.96, p<.01$; attitude index, $F(1,159)=7.86, M S_{\mathrm{e}}=$ $0.80, p<.01$; intention to initiate the next eating out incident, $\left.F(1,159)=12.41, M S_{\mathrm{e}}=2.13, p<.01\right]$.

The means driving the three-way interaction followed the expected pattern. Specifically, satisfaction ratings in the recent time frame condition were higher when the participants were asked to recall $2\left(M_{2}=5.5\right)$ versus 10 $\left(M_{10}=4.7\right.$; contrast, $\left.p<.01\right)$ instances of eating at regular SDRs, the more positive experience. The pattern was reversed for the less positive experience: FFRs $\left(M_{2}=4.9\right.$, $M_{10}=5.9$; contrast, $\left.p<.05\right)$. These effects held only for recent experiences. When queried about a less recent time frame, the differences disappeared $\left(\mathrm{SDR}, M_{\mathrm{SDR}-2}=\right.$ $4.8, M_{\mathrm{SDR}-10}=5.1 ; \mathrm{FFR}, M_{\mathrm{FFR}-2}=5.6, M_{\mathrm{FFR}-10}=5.9$; contrast, $p \mathrm{~s}>.10$ ). The means for the other dependent measures followed a similar pattern: A shorter listing task improved attitudes for a more positive experience; a longer one improved attitudes for a less positive experi- 
Table 5

Experiment 2 Results: Attitudes and Behavioral Intentions

\begin{tabular}{|c|c|c|c|c|c|c|c|c|c|}
\hline \multirow[b]{3}{*}{ Measure } & & \multicolumn{4}{|c|}{ Sit-Down Restaurants } & \multicolumn{4}{|c|}{ Fast-Food Restaurants } \\
\hline & & \multicolumn{2}{|c|}{ Recall 2} & \multicolumn{2}{|c|}{ Recall 10} & \multicolumn{2}{|c|}{ Recall 2} & \multicolumn{2}{|c|}{ Recall 10} \\
\hline & & $M$ & $S D$ & $M$ & $S D$ & $M$ & $S D$ & $M$ & $S D$ \\
\hline \multirow[t]{2}{*}{ Satisfaction with eating out experiences } & Recent & 5.5 & 0.8 & 4.7 & 1.2 & 4.9 & 1.1 & 5.9 & 0.8 \\
\hline & Not recent & 4.8 & 1.1 & 5.0 & 1.1 & 5.6 & 0.6 & 5.9 & 0.8 \\
\hline \multirow{2}{*}{ Attitude toward eating out (four-item index; $\alpha=.87$ ) } & Recent & 5.9 & 0.7 & 5.1 & 1.4 & 5.1 & 1.3 & 5.8 & 0.8 \\
\hline & Not recent & 6.0 & 0.6 & 6.0 & 0.8 & 5.9 & 0.5 & 5.9 & 0.6 \\
\hline \multirow[t]{2}{*}{ Likelihood of initiating next eating out incident* } & Recent & 6.2 & 0.8 & 4.9 & 1.8 & 4.8 & 1.4 & 5.8 & 1.4 \\
\hline & Not recent & 4.7 & 1.5 & 4.7 & 1.7 & 5.9 & 0.8 & 4.9 & 1.8 \\
\hline \multirow[t]{2}{*}{ Likelihood of choosing a sit-down restaurant* } & Recent & 6.1 & 1.1 & 5.2 & 1.4 & 5.3 & 1.4 & 4.8 & 1.5 \\
\hline & Not recent & 4.9 & 1.3 & 5.3 & 1.5 & 5.0 & 1.6 & 4.4 & 1.4 \\
\hline \multirow[t]{2}{*}{ Likelihood of choosing a fast-food restaurant* } & Recent & 4.4 & 1.8 & 3.9 & 1.9 & 3.1 & 1.5 & 4.8 & 1.8 \\
\hline & Not recent & 3.6 & 1.9 & 3.3 & 1.8 & 3.9 & 1.9 & 4.3 & 1.2 \\
\hline
\end{tabular}

${ }^{*}$ Elicited using $1=$ not at all, $7=$ very.

ence, but only when recent events were recalled (see Table 5).

Estimates of behavioral frequencies for the average person. In contrast to the pattern for the respondents' own behavioral frequencies, Exp, and attitudes and intentions, we expected only main effects of number of items recalled and type of experience when judgments were being made about another person. We used two dependent measures to elicit behavioral frequencies for the average person: an open-ended estimate of how frequently the average person ate out in a month and an SF measure on a 7point scale, with higher numbers indicating a higher frequency. Means by condition are provided in Table 6 . The two measures were subjected to $2 \times 2 \times 2$ ANOVAs. Both analyses yielded a predicted main effect of number of items recalled [open-ended, $F(1,159)=4.36, M S_{\mathrm{e}}=$ $68.31, p<.01$; SF, $F(1,159)=6.32, M S_{\mathrm{e}}=0.94, p<$ .05 ), so that reported frequency for the average person was higher when the participants were asked to recall 10 instances, using the open-ended scale $\left(M_{10}=16.2\right.$ vs. $M_{2}=13.5$; $)$ or the SF scale $\left(M_{10}=5.8\right.$ vs. $\left.M_{2}=5.5\right)$. In addition, there was a main effect of valence [open-ended, $F(1,159)=9.74, p<.01$; SF, $F(1,159)=8.74, p<.01]$, so that the estimated frequencies were higher for FFRs than for SDRs with the open-ended scale measure $\left(M_{\mathrm{FFR}}=\right.$ 16.9 vs. $\left.M_{\mathrm{SDR}}=12.9\right)$, as well as with the SF scale measure $\left(M_{\mathrm{FFR}}=5.9\right.$ vs. $\left.M_{\mathrm{SDR}}=5.4\right)$. Importantly, no other effects were significant: The recency of the time frame manipulation did not interact with the number of items recalled in the manner in which it did for estimates for behavioral frequency judgments about one's self.
To summarize, the data supported our overall conceptual framework that ease-of-retrieval effects are eliminated when the discrepancy between expected and experienced ease of retrieval can be attributed away to either the (lack of) recency of an event or the fact that judgments are being made for another person. Specifically, when instances were difficult to recall but were expected to be easy to recall, the participants reported lower frequencies and expenditures for eating out at restaurants, regardless of the valence of the information retrieved (i.e., type of the restaurant). However, when instances were actually difficult to recall but were also expected to be difficult to recall, the experienced difficulty, although felt, was uninformative for self-judgments. This was the case for less recent events. The results of this experiment also indicate that recency interacted with ease of retrieval to determine self-judgments, but not estimates of an "average" other's behavior. Furthermore, the valence of information retrieved interacted with the ease of retrieval, as well as with the recency of the time frame of events, to affect attitudes and intentions. When positive experiences were recalled, attitudes and intentions were highest when the participants were asked to recall two incidents in the recent past. However, when less positive incidents were recalled, the results were reversed.

\section{GENERAL DISCUSSION}

The two experiments reported in this article show that the ease of retrieval of information in memory (i.e., the ease with which something can be brought to mind), as

Table 6

Experiment 2 Results: Means and Standard Deviations of Estimates of Behavioral Frequencies for the Average Person

\begin{tabular}{|c|c|c|c|c|c|c|c|c|c|}
\hline \multirow[b]{3}{*}{ Measure } & & \multicolumn{4}{|c|}{ Sit-Down Restaurants } & \multicolumn{4}{|c|}{ Fast-Food Restaurants } \\
\hline & & \multicolumn{2}{|c|}{ Recall 2} & \multicolumn{2}{|c|}{ Recall 10} & \multicolumn{2}{|c|}{ Recall 2} & \multicolumn{2}{|c|}{ Recall 10} \\
\hline & & $M$ & $\overline{S D}$ & $M$ & $\overline{S D}$ & $M$ & $\overline{S D}$ & $M$ & $S D$ \\
\hline \multirow[t]{2}{*}{ Open-ended frequency for a month } & Recent & 12.9 & 6.3 & 16.3 & 10.2 & 16.0 & 9.0 & 17.8 & 9.3 \\
\hline & Not recent & 10.2 & 4.5 & 12.2 & 6.1 & 15.0 & 10.2 & 18.6 & 8.2 \\
\hline \multirow[t]{2}{*}{ Closed-ended frequency $(1=$ rarely; $7=$ frequently $)$} & Recent & 5.4 & 1.0 & 5.9 & 1.2 & 5.7 & 0.9 & 6.0 & 0.7 \\
\hline & Not recent & 5.1 & 1.2 & 5.3 & 1.6 & 5.7 & 0.6 & 6.1 & 0.6 \\
\hline
\end{tabular}


distinct from the valence of the information itself (indicative of the effects of information content), affect behavioral frequency reports, but only for recent behaviors, and only for estimates of one's own behavior. Experiment 1 showed that when people can recall incidents of a behavior easily, they report a higher frequency of engaging in the behavior. In addition, when such recalled incidents are positive, attitudes and behavioral intentions are more positive as well. These results are reversed when the information recalled is negative. Experiment 2 demonstrated that the effects noted in Experiment 1 are greater when events occur in the recent past, rather than in the distant past. This is in line with our proposed model, which suggests that the recency of an event allows people to attribute the felt difficulty of recall to the timing of the events, rather than to the overall frequency of the events. At the same time, we obtain a further understanding of the process by which the twin antecedents of accessibility work to affect the estimated frequency of a behavior. We showed that judgments about self are based on experiential memory-based information, whereas inferences about an average person are made using the information available in the context. The valence of the behaviors then interacts with the inferred frequency of the behaviors to affect related attitudes and intentions.

Building on the current theory of the informative value of ease of retrieval (see the review by Schwarz, 1998), we suggest that the informative value of ease of retrieval is a function of expectations of its informativeness in the domain of behavioral frequency judgments. In the person perception literature, Schwarz et al. (1991) demonstrated that content and ease of retrieval affect subjective self-judgments. We add to the evidence that frequency judgments (i.e., seemingly "objective" phenomena) are amenable to biases in much the same way as are self-perceptions and attitudes (see also Aarts \& Dijksterhuis, 1999), and we shed light on the process by which ease of retrieval affects behavioral frequency judgments.

To summarize, the informativeness of the ease of retrieval as a cue can be examined by asking the following. Why is it informative? When will it be informative? For whom is it informative? For what is it informative? And is it symmetrically informative when it is easy versus difficult? We argue that ease of retrieval is informative because it diverges from expectations of recall difficulty. On the basis of this argument, we showed that it will be more informative for recent events (which are expected to be easier to recall) than for distant events. Our model and experiments provide answers to the first two questions and provide a framework for thinking about the remaining ones.

\section{Study Limitations and Areas of Future Research}

We provide tentative evidence that ease of retrieval is more informative for self-judgments than for otherjudgments. However, since in the experiments, we used an "average" person as the target "other," these results need to be replicated by examining effects across a range of "other" persons differing on their proximity to the target, to assess whether schematic similarity or knowledge of another person's behaviors leads to differential effects for oneself versus another.

Prior research has essentially focused on the informativeness of ease of retrieval for frequency judgments. However, our framework suggests that frequency is one of multiple domains for which this experienced ease of retrieval can be informative. Others include recency and the quality of one's own memory. For example, research in the area of telescoping (i.e., the tendency of people to see an event as having occurred more recently than it did) suggests that pinpointing exactly when an event took place is a difficult task (see Brown \& Schopflocher, 1998). In such a case, difficulty of retrieval may be used to infer the recency of the event. This is an avenue for future research.

Furthermore, the possibility exists that the discrepancy is attributed to a misperception of recall experience. That is, people modify the experienced ease or difficulty of recalling information, rather than their expectancies of it, thinking "Well, that was not as difficult as I thought while I was doing it." This is an intriguing possibility that may occur when the experience is tensile and subject to reinterpretation but the expectations are less so. We suggest that this question can be an area for future research.

Finally, another question for future research is whether ease and difficulty of retrieval will have symmetric effects. For example, when a historical event, a distant product experience, or an infrequent one is recalled, the baseline expectation may be that specific features of the episode would be difficult to recall. In such contexts, the ease of retrieval, rather than the difficulty of retrieval, of information may be particularly informative. The focus of this article was on situations in which recalling information was experienced as more difficult than was expected; that is, we focused on the informative value of recall difficulty. However, similar (if not symmetric) effects can be posited for when information is expected to be difficult to recall and comes to mind easily. Such a discrepancy may well be attributed to the features of the specific stimuli (or event) that made it memorable (e.g., "That must have been important/interesting/unusual"), allowing for it to be easily recalled.

\section{REFERENCES}

Aarts, H., \& DiJksterhuis, A. (1999). How often did I do it? Experienced ease of retrieval and frequency estimates of past behavior. Acta Psychologica, 103, 77-89.

Blair, E., \& Burton, S. (1987). Cognitive processes used by survey respondents to answer behavioral frequency questions. Journal of Consumer Research, 14, 280-288.

Brewin, C. R., \& STOKOU, L. (2002). Validating reports of poor childhood memory. Applied Cognitive Psychology, 16, 509-514.

Brown, N. R., \& Schopflocher, D. (1998). Event clusters: An organization of personal events in long-term memory. Psychological Science, 9, 470-475.

Burton, S., \& Blair, E. (1991). Task conditions, response formulation processes, and response accuracy for behavioral frequency questions in surveys. Public Opinion Quarterly, 55, 50-79. 
Higgins, E. T. (1989). Knowledge accessibility and activation: Subjectivity and suffering from unconscious sources. In J. S. Uleman \& J. A. Bargh (Eds.), Unintended thought (pp. 75-123). New York: Guilford.

HintzMAN, D. L. (2001). Judgments of frequency and recency: How they relate to reports of subjective awareness. Journal of Experimental Psychology: Learning, Memory, \& Cognition, 27, 1347-1358.

HintZman, D. L. (2003). Judgments of recency and their relation to recognition memory. Memory \& Cognition, 31, 26-34.

Jacoby, L. L., Kelley, C., Brown, J., \& JasechKo, J. (1989). Becoming famous overnight: Limits on the ability to avoid unconscious influences of the past. Journal of Personality \& Social Psychology, 56, 326-338.

Kelley, C. M., \& LindSAy, D. S. (1993). Remembering mistaken for knowing: Ease of retrieval as a basis for confidence in answers to general knowledge questions. Journal of Memory \& Language, 32, 1-24.

Menon, G. (1993). The effects of accessibility of information in memory on judgments of behavioral frequencies. Journal of Consumer Research, 20, 431-440.

Menon, G. (1997). Are the parts better than the whole? The effects of decompositional questions on judgments of frequent behaviors. Journal of Marketing Research, 32, 335-346.

Menon, G., Block, L., \& Ramanathan, S. (2002). We're at as much risk as we're led to believe: Effects of message cues on judgments of health risk. Journal of Consumer Research, 28, 533-549.

Menon, G., \& Raghubir, P. (2003). Ease of retrieval as an automatic input in judgments: A mere accessibility framework? Journal of Consumer Research, 30, 230-243.

Menon, G., Raghubir, P., \& Schwarz, N. (1995). Behavioral frequency judgments: An accessibility-diagnosticity framework. Journal of Consumer Research, 22, 212-228.

Menon, G., Raghubir, P., \& Schwarz, N. (1997). How much will I spend? Factors affecting consumers' estimates of future expense. Journal of Consumer Psychology, 6, 141-164.

Raghubir, P., \& MEnON, G. (1996). Asking sensitive questions: The effects of type of referent and frequency wording in counterbiasing methods. Psychology \& Marketing, 13, 633-652.

Raghubir, P., \& Menon, G. (1998). AIDS and me, never the twain shall meet: The effects of information accessibility on judgments of risk and advertising effectiveness. Journal of Consumer Research, 25, 52-63.

Raghubir, P., \& Menon, G. (2001). Framing effects in risk perception of AIDS. Marketing Letters, 12, 145-155.

Rothman, A. J., \& Schwarz, N. (1998). Constructing perceptions of vulnerability: Personal relevance and the use of experiential information in health judgments. Personality \& Social Psychology Bulletin, 24, 1053-1064.

SCHWARZ, N. (1990). Assessing frequency reports of mundane behavior: Contribution of cognitive psychology to questionnaire construction. In C. Hendrick \& M. S. Clark (Eds.), Research methods in personality and social psychology (pp. 98-119). Newbury Park, CA: Sage.

SCHWARZ, N. (1998). Accessible content and accessibility experiences: The interplay of declarative and experiential information in judgment. Personality \& Social Psychology Review, 2, 87-99.

Schwarz, N., Bless, H., Strack, F., Klumpp, G., RittenauerSchatKa, H., \& SimOns, A. (1991). Ease of retrieval as information: Another look at the availability heuristic. Journal of Personality \& Social Psychology, 61, 195-202.

Schwarz, N., Hippler, H.-J., Deutsch, B., \& Strack, F. (1985). Response categories: Effects on behavioral reports and comparative judgments. Public Opinion Quarterly, 49, 388-395.

SkURniK, I., Schwarz, N., \& Winkielman, P. (2000). From feelings to judgments: The role of naïve beliefs. In H. Bless \& J. Forgas (Eds.), The message within: The role of subjective experience in social cognition and behavior (pp. 162-175). Philadelphia: Psychology Press.

Sudman, S., \& BRAdBuRn, N. M. (1974). Response effects in surveys: A review and synthesis. Chicago: Aldine.

Tversky, A., \& Kahneman, D. (1973). Availability: A heuristic for judging frequency and probability. Cognitive Psychology, 5, 207232.

WäNKe, M., BoHNER, G., \& JuRKowITSCH, A. (1997). There are many reasons to drive a BMW: Does imagined ease of argument generation influence attitude? Journal of Consumer Research, 24, 170-177.

Whittlesea, B. W. A., \& Williams, L. D. (1998). Why do strangers feel familiar, but friends don't? The unexpected basis of feelings of familiarity. Acta Psychologica, 98, 141-166.

Whittlesea, B. W. A., \& Williams, L. D. (2000). The source of feelings of familiarity: The discrepancy-attribution hypothesis. Journal of Experimental Psychology: Learning, Memory, \& Cognition, 26, 547-565.

Wilson, T. D., \& BrekKe, N. (1994). Mental contamination and mental correction: Unwanted influences on judgments and evaluations. Psychological Bulletin, 116, 117-142.

WinkIELMAN, P., \& Schwarz, N. (2001). How pleasant was your childhood? Beliefs about memory shape inferences from experienced difficulty of recall. Psychological Science, 12, 176-179.

Winkielman, P., Schwarz, N., \& Belli, R. F. (1998). The role of ease of retrieval and attribution in memory judgments: Judging your memory as worse despite recalling more events. Psychological Science, $\mathbf{9}$, 124-126.

\section{NOTES}

1. Note that an analogous set of predictions can be made for when the experience of recalling information is easier than expected.

2 . Three additional situations are possible but are not tested in the study. These are the following. (1) If people experience difficulty when they expect information to be easily retrievable, they will subjectively reinterpret recency when frequency is less ambiguous than recency; (2) if people experience difficulty when they expect information to be easily retrievable, they will infer that they have a poor memory when frequency and recency are unambiguous; and (3) if people experience difficulty when they expect information to be easily retrievable, they may modify the experienced ease or difficulty of recalling information. Menon and Raghubir's (2003) results suggest that once the ease of retrieval has entered as an input into a judgment, it cannot be corrected (mental contamination models; see Wilson \& Brekke, 1994), making it difficult to recast experienced difficulty.

3. A pretest among 75 participants drawn from the same pool as that used in the experiment demonstrated that expenses on eating out at restaurants was the second highest expense category out of 17 categories. On average, participants reported spending $\$ 32.05$ every week on eating out, $\$ 25.93$ on purchase of groceries, and $\$ 37.87$ on purchasing clothes.

4. Six participants were not able to recall the specified number of items. However, the ease-of-retrieval manipulation affected people similarly, irrespective of whether they had completed the recall task. Therefore, all the participants were included in the analyses.

5. Respondents in both the fast-food and the sit-down restaurant conditions estimated the amount they spent in both valence conditions (fast-food and sit-down restaurants). The results show that an effect obtains for the category of restaurant that was not recalled similar to that for the category of restaurant that was recalled. This pattern suggests the possibility that participants use ease of retrieval to make judgments related not only to a specific content domain (type of restaurant recalled), but also to related domains (type of restaurant not recalled). This could be because expense estimates for a subcategory (e.g., fast food) affect estimates for the larger product category (restaurants in general) and, through this, affect estimates for a related subcategory (e.g., sit-down restaurants). It could also be a more direct inferential route based on a relationship between the two domains (e.g., if I spend $\$ 100$ in sit-down restaurants, I probably spend $\$ 50$ in fast-food restaurants).

(Manuscript received July 12, 2002; revision accepted for publication August 15, 2004.) 